\title{
Global Surface Geostrophic Ocean Currents Derived from Satellite Altimetry and GOCE Geoid
}

\author{
J. M. SÁNCHEZ-REALES, ${ }^{1}$ M. I. VIGO,${ }^{1}$ S. JIN, ${ }^{2}$ \\ AND B. F. CHAO ${ }^{3}$ \\ ${ }^{1}$ Applied Mathematics Department, University of Alicante, Alicante, Spain \\ ${ }^{2}$ Chinese Academy of Science, Shanghai, China \\ ${ }^{3}$ Academic Sinica, Taipai, Taiwan
}

\begin{abstract}
The surface geostrophic currents $(S G C)$ can be derived via the principle of geostrophy from the dynamic height of the ocean, or the deviation of the true, variable sea surface height with respect to the Earth's static geoid, both of which can be measured by geodetic means. Here we calculate the Mean Dynamic Topography (MDT) by subtracting the geoid height determined by the GOCE satellite mission from the Mean Sea Surface Topography (MSST) derived from multi-satellite ocean altimetry (T/P, Jason 1/2, ERS1/2, GEOSAT). Results for SGC are compared with those obtained from a GRACE-based mean geoid, as well as with the mean circulation patterns from measurements done by in situ drifter buoys and from simulations of the ECCO Ocean General Circulation Model. We found GOCE-based geoid solution clearly leads to significant improvements in the spatial resolution of SGC globally except in the Equatorial band where special filtering may be needed, with current velocities and spatial patterns closest to the in situ measurements of currents, compared with the GRACE-based results or ECCO model simulations that give significantly weaker Values with lower spatial resolution.
\end{abstract}

Keywords GOCE, geostrophic currents, ocean dynamic topography, ocean circulation, satellite altimetry

\section{Introduction}

Ocean currents play a key role in determining the Earth's climate pattern and its evolution, and as such they have long been a quest of investigation by climatologists, oceanographers, and geophysicists and have generated interest from the maritime commercial and fishery enterprises. By the principle of geostrophy of the ocean, the surface geostrophic currents (SGC) can be derived directly from the dynamic height of the ocean or the deviation of the true, variable sea surface height with respect to the Earth's static geoid, both of which can be measured by geodetic means. Specifically, the Mean Dynamic Topography (MDT) is determined by subtracting the geoid height from the Mean Sea Surface Topography (MSST) derived from ocean altimetry. The mean SGC can then be derived from the MDT via the geostrophic flow equation.

Received 16 January 2012; accepted 30 May 2012.

Address correspondence to Jose Maria Sánchez-Reales, Dto. Matemática Aplicada, EPS, Universidad de Alicante, Ctra San Vicente del Raspeig s/n, Ap. Correos 99, 03080, Alicante, Spain. E-mail: jms.reales@ua.es 
Great advances in space geodetic techniques in recent decades have enabled the determination of both quantities, particularly via satellite observations that have nearly global and continuous coverage. With the availability of precise altimetric measurements of sea surface height for two decades, the critical requirement for obtaining the SGC has been a solution, or model, for the geoid with sufficient accuracy and spatial resolution.

The determination of the Earth's static geoid has seen a breakthrough since 2002, via the Gravity Recovery and Climate Experiment (GRACE) satellite mission (although its principal aim is the Earth's time-variable gravity; Tapley et al. 2004). Together with the available ocean altimetric data for the Sea Surface Height (SSH), long-term SGC has been successfully solved for global as well as basin scales (Tapley et al. 2003; Maximenko et al. 2009; Birol et al. 2005). However, considering the limitations of the GRACE-derived geoid, more detailed understanding of the ocean dynamics demands higher spatial resolutions than what is possible from GRACE.

Launched in March 2009 as the first core Earth Explorer mission in the European Space Agency's Living Planet program, the Gravity and steady-state Ocean Circulation Explorer (GOCE) satellite mission brings about a significantly higher spatial resolution than GRACE. GOCE has as its major goal to determine the Earth's mean geoid accurate to 1-2 cm in height at spatial resolution finer than $100 \mathrm{~km}$ (Drinkwater et al. 2003). Three approaches with different purposes lead to somewhat different geoid models for GOCE (Pail et al. 2011): the direct method (DIR) defined up to degree/order 240, in which the GOCE data are included to improve a reference background field; the time-wise approach (TIW) to degree/order 224, in which no external gravity field information is included; and the space-wise method (SPW) to degree/order 210 in which some a priori knowledge is included but only for the low degrees. Bingham et al. (2011) used the first generation GOCE TIW solution to assess the performance of GOCE in terms of the ocean MDT and associated SGC in the North Atlantic Ocean. Knudsen et al. (2011) used the first generation GOCE DIR solution to estimate global SGC through a Gaussian filtered MDT. Both applications demonstrated the superiority of the GOCE geoid over the GRACE geoid.

We focus on the evaluation of the solved SGC in terms of spatial resolution to the extent allowed by the GOCE data. We use the first generation GOCE DIR solution for the reason that the use of a priori information will make the model less noisy for higher harmonic degrees that correspond to finer spatial scales to be resolved. Note that the MSST from altimetry is determined in a much higher resolution than the geiod derived from GOCE (or GRACE for that matter), which acts as the background reference surface here. Hence any remaining short wavelength noise in the latter would corrupt our results. In addition there is a need to homogenize the length scales in both the MSST and the geoid datasets. Thus we low-pass filtered the data by a Gaussian filter of half-wavelength of $\sim 83 \mathrm{~km}$ (corresponding to a maximum spherical harmonic degree of 240) which will retain all wavelengths solved by the geoid model. Our SGC results will be compared with those determined via the stateof-the-art GRACE geoid model, as well as in situ measurements provided by drifter buoys and a velocity field derived from the ECCO ocean general circulation model (OGCM).

\section{Data and Methodology}

\subsection{Geoid N}

The geoid height can be expressed approximately as

$$
N(\vartheta, \lambda)=\frac{G M}{a g} \sum_{n=0}^{N \max } \sum_{m=0}^{n}\left(\Delta C_{n m} \cos m \lambda+\Delta S_{n m} \sin m \lambda\right) P_{n m}(\cos \vartheta)
$$


where $(\vartheta, \lambda)=$ (geocentric co-latitude, longitude) of the field point; $\left(\Delta C_{n m}, \Delta S_{n m}\right)$ are the normalized spherical harmonic Stokes coefficients for which $P_{n m}$ is the Legendre polynomial for degree $n$ and order $m$ up to the maximum degree Nmax, GM and $g$ are, respectively, the gravitational constant times total mass and the normal gravitational acceleration of the Earth; and $a$ is the equatorial radius to which the Earth's parameters in Eq. (1) are converted in reference to the TOPEX/Poseidon ellipsoid (Heiskanen and Moritz 1967; Hughes and Bingham 2006; Smith 1998). Here we adopt the first-generation GOCE gravity field solutions of the Stokes coefficients complete to Nmax $=240$ (DIR solution). A complete description of the GOCE products and applied corrections are given in detail in EGG-C (2009).

The direct method to derive the GOCE geoid model builds upon a priori background models-EIGEN05C (Foerste et al. 2008) in the preset case. For the ocean, the EIGEN05C is based on a combination of GRACE gravity observations and altimetric SSH measurements. Therefore, the noise in the higher degrees of the GOCE geoid model will be reduced since it contains altimetric measurements that are able to resolve much smaller scales than GOCE does. Moreover, since we are combining this geoid model with an altimetric MSST, some noisy smaller spatial-scale signals are expected to be cancelled in the MDT. We shall evaluate both GRACE and GOCE geoid models in a quarter degree grids to match the grid of the altimetry data.

For the GRACE-based SGC to be compared with the GOCE-based SGC, we adopt the long-term mean ITG-GRACE2010S static gravity model (Institut für Geodäsle und Geoinformation, University of Bonn; see http://www.igg.uni-bonn.de/apmg/index.php?id=itggrace2010), based on seven years of GRACE observations (August 2002-August 2009) and complete to Nmax $=180$. Nevertheless, we found a strong zonal and meridional noise that contaminates the latter, so we choose Nmax $=160$ avoiding much of the zonal noise, although some meridional noise is still present especially in the Equatorial band.

Usual corrections (Kurtenbach et al. 2009; Bettadpur 2007a, 2007b) have been applied in processing the GOCE and GRACE data in obtaining the gravity models, including solidEarth and ocean tides, the pole tides, and atmospheric and oceanic pressure variations. For the GRACE geoid the mean of the AOD1B product is restored afterwards and therefore the model contains the complete gravity signal (including atmosphere and ocean masses). For the GOCE geoid the IB effect is estimated in three separate cases, based respectively on the atmospheric data from the European Center for Medium-range Weather Forecast (ECMWF) operational analysis, the bottom pressure estimates from the Ocean Model for Circulation and Tides (OMCT) model (Thomas 2002), and a GRACE monthly gravity field time series (EGG-C 2009).

\subsection{Mean Sea Surface Topography MSST}

We adopt the weekly, multi-satellite solution of the sea level anomaly, given on a quarter-degree grid for the period October 14, 1992-October 1, 2010, from ERS-1/2, Topex/Poseidon (T/P), ENVISAT and Jason-1/2 (Aviso, http://www.aviso.oceanobs.com, Version 03, May 2011). We compute the MSST simply by time-averaging these data and adding to them their original reference height of CLS01-MSS. The original CLS01-MSS was estimated from seven years of T/P (1993-1999), five years of ERS-1/2, and two years of Geosat (Hernandez and Shaeffer 2001) data; we extend it to longer than 18 years and interpolated it via a 2-D cubic spline to match the corresponding geographical distribution for the sea level anomaly data.

The altimetric data as provided are those after the application of the usual corrections, including the ionospheric delay, dry and wet tropospheric corrections, solid-Earth and ocean 
tides, ocean tide loading, pole tides, IB response of the ocean, electromagnetic and sea-state biases, and instrumental corrections. As we did with the geoid, we expand the MSST into spherical harmonics up to degree Nmax, where the areas not covered by the altimetric data (land and small inland seas/lakes and the highest latitudes) were filled with geoid values.

\subsection{Mean Dynamic Topography MDT and Surface Geostrophic Current SGC}

MDT is obtained simply by subtracting the geoid from MSST, that is, MDT $=$ MSST $N$, which is readily conducted in the spectral domain in terms of the spherical harmonic coefficients (Bingham et al. 2008). Here a Gaussian smoothing of radius $20000 \mathrm{~km} / \mathrm{Nmax}$ was applied (in the spectral domain) to both MSST and $N$ to ensure homogenization of the length scale.

The SGC velocity $U_{s}=u_{s}+i v_{s}$, where $\left(u_{s}, v_{s}\right)=$ (zonal or eastward, meridional or northward) components along the $x$ and $y$ directions, follows immediately from the geostrophy, i.e., the balance of the pressure gradient force with the Coriolis force (e.g., Gill 1982):

$$
\begin{aligned}
& u_{s}=-\frac{g}{f} \frac{\partial M D T}{\partial y}, \\
& v_{s}=\frac{g}{f} \frac{\partial M D T}{\partial \mathrm{x}},
\end{aligned}
$$

where $f=2 \Omega \sin \varphi$ is the latitude-dependent Coriolis parameter.

The horizontal Coriolis force vanishes at the equator; the numerical computation of (2) becomes unstable when $\varphi \rightarrow 0$. We treat this problem by estimating the SGC for the equatorial band $\left[5^{\circ} \mathrm{S} 5^{\circ} \mathrm{N}\right]$ following the method proposed by Lagerloef et al. (1999). Thus, by the second derivative of (2),

$$
\beta U_{b}+\beta y \frac{\partial U_{b}}{\partial y}=i g \frac{\partial^{2} Z_{b}}{\partial y^{2}},
$$

where $Z_{b}=\partial M D T / \partial y+i \partial M D T / \partial x$ and $U_{b}=u_{b}+i v_{b}$ in the equatorial band, and $f=\beta y$. We approximate the solution of (3) by a polynomial expansion,

$$
\begin{aligned}
& Z_{b}=Z_{0}+Z_{1} \vartheta+Z_{2} \vartheta^{2}+Z_{3} \vartheta^{3}, \\
& U_{b}=\frac{i g}{\beta L}\left(Z_{1}+Z_{2} \vartheta+Z_{3} \vartheta^{2}\right),
\end{aligned}
$$

where $L \sim 111 \mathrm{~km}$ represents $1^{\circ}$ at the equator. Then, the SGC are obtained by weighting $U_{s}$ and $U_{b}$ by

$$
\left(u_{g}, v_{g}\right)=\omega_{b}\left(u_{b}, v_{b}\right)+\omega_{s}\left(u_{s}, v_{s}\right)
$$

where

$$
\begin{aligned}
& \omega_{b}=\exp \left[-\left(\lambda / \lambda_{\mathrm{c}}\right)^{2}\right], \\
& \omega_{s}=1-\omega_{b},
\end{aligned}
$$

defines a Gaussian weighting function where the length scale $\lambda_{\mathrm{c}}\left(\right.$ here $\left.\lambda_{\mathrm{c}}=2.2^{\circ}\right)$ is selected to distribute the weights in (5). 


\subsection{ECCO Data}

The SSH simulated using the global OGCM ECCO (Adcroft et al. 2002) is used here to determine the SGC in a similar manner (except that the geoid is not involved here). The ECCO model (see, ecco.jpl.nasa.gov) provides several sets of solutions; here we used the kf080 solution which assimilates SSH anomalies from the altimetry data through a Kalman filter (Fukumori 2002) accounting for the model errors associated with inaccuracy in time-variable wind forcing. Since ECCO is a global non-eddy-resolving model, we use here the simulated SSH to derive the SGC instead of the horizontal velocities provided by the direct model outputs. Hence, we use 10-day "maps" of SSH in the time span January 1993-December 2010 (same as altimetry) to determine a long-term average SSH in a nearglobal coverage of latitudes from $80^{\circ} \mathrm{S}$ to $79^{\circ} \mathrm{N}$ on a homogeneous 1 degree grid filled in using a 2D cubic splines interpolation. The horizontal velocity components were then obtained via geostrophy (Eq. 2).

\subsection{In Situ Drifter Buoy Data}

An annual climatology for the ocean surface currents based on in situ drifter buoy observations is provided by the Global Drifter Program on a $1^{\circ}$ grid covering latitudes between $73^{\circ} \mathrm{S}$ and $85^{\circ} \mathrm{N}$ (www.aoml.noaa.gov/phod/dac/drifter_climatology.html; also Sybrandy and Niiler 1991; Niiler 2001). Daily winds from the NCEP/NCAR reanalysis
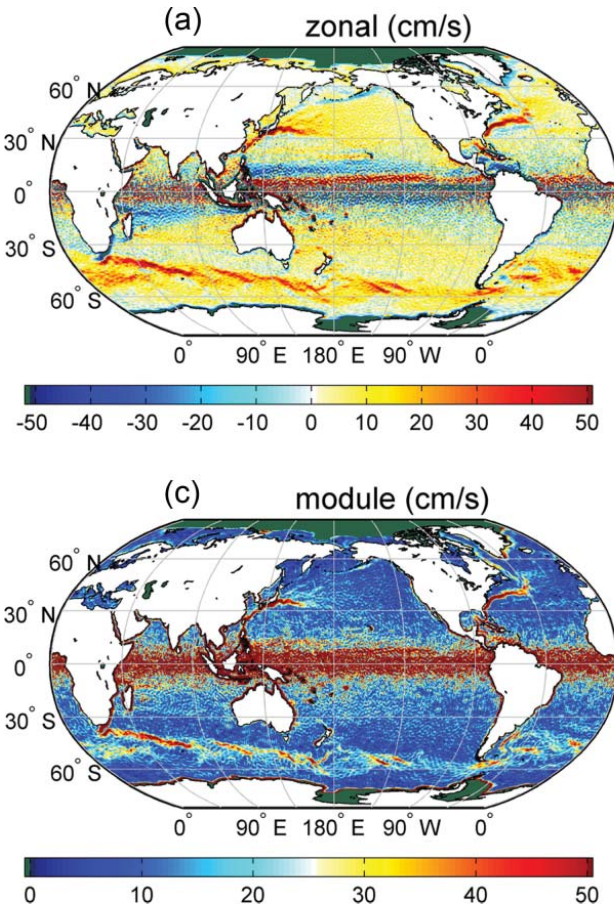

(b) meridional $(\mathrm{cm} / \mathrm{s})$

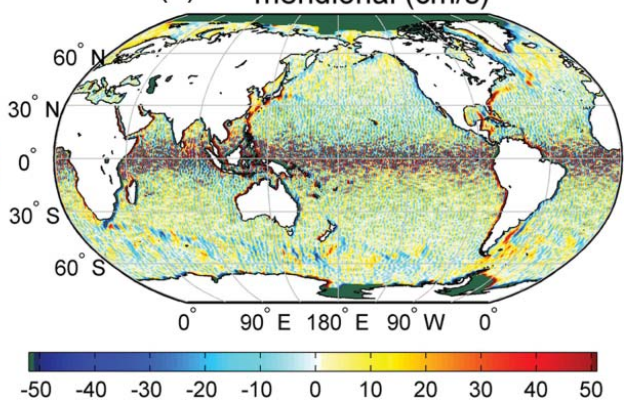

(d)

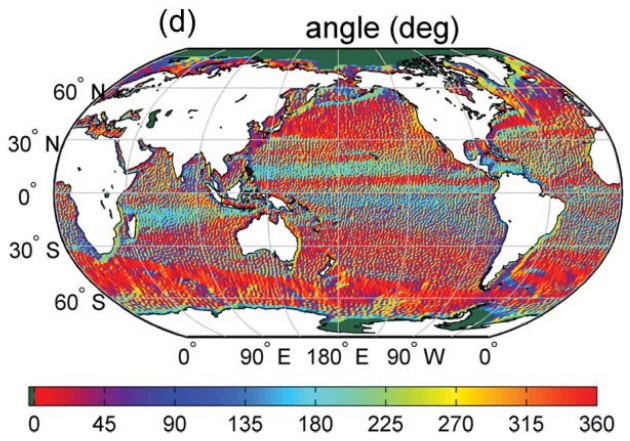

Figure 1. (a) Zonal component, or east-speed $u_{\mathrm{g}}$; (b) meridional component, or north-speed $v_{\mathrm{g}}$; (c) amplitude of horizontal velocity; (d) phase angle (from east direction), of the SGC estimated using $M D T=$ Altimetric MSST minus GOCE-derived geoid $N$. (Color figure available online.) 
were interpolated onto the drifter positions and used to estimate and remove the slip associated with the direct wind forcing (Niiler and Paduan 1995; Pazan and Niiler 2000). Wind stress and the local Coriolis parameter were used to estimate the Ekman component (Ralph and Niiler 1999), which is subtracted to generate a separate set of Ekman -free, surface geostrophic velocity field.

Here it should be noted that, in contrast to GOCE-, GRACE-, and ECCO-derived currents which share the same time span, the drifter observations were made from about 1,000 drifters nonuniformly distributed in space and time. Therefore, some artifact discrepancies may exist when comparing the SGC estimates, particularly for areas with strong inter-annual to decadal variations (e.g., Qiu and Chen 2005).

\section{Results}

\subsection{Global Mean SGC}

Figure 1 gives our GOCE-based solution of the global mean SGC computed via Eq. (2): 1(a) for the zonal (eastward) and 1(b) for the meridional (northward) components, whereas $1(\mathrm{c})$ and 1(d) show, respectively, the corresponding amplitude and direction angle (counterclockwise from the east direction). Except the equatorial band (latitudes lower than $10^{\circ}-15^{\circ}$ ), all the main features of the global SGC are clearly resolved in Figure 1 . Circulation in the equatorial band is not well resolved due to the high noise in the meridional

(a)

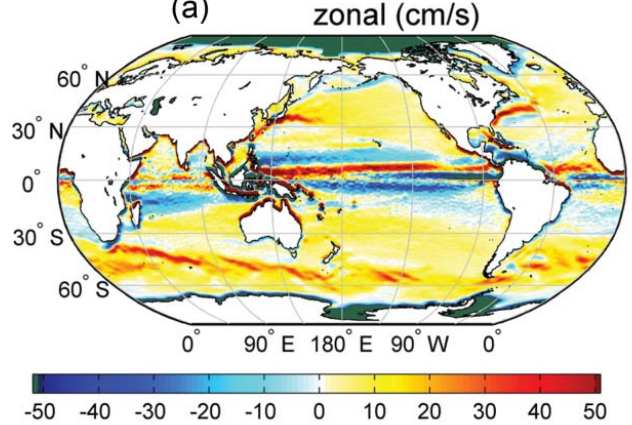

(c)

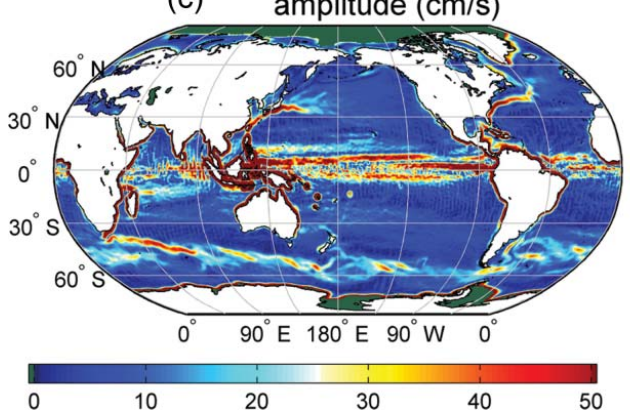

(b)

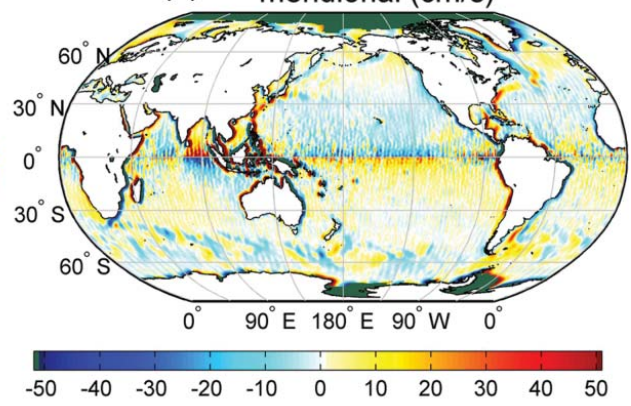

(d)

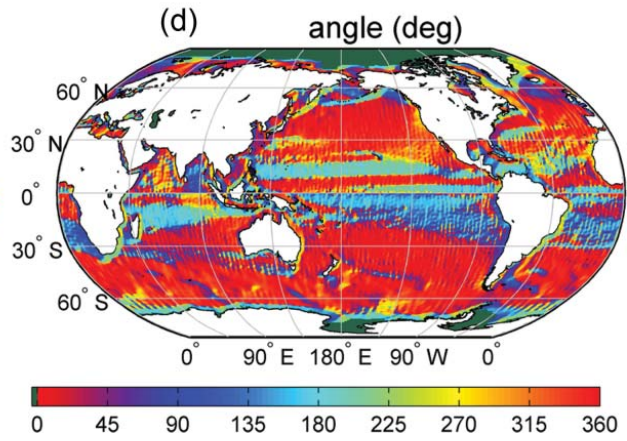

Figure 2. (a) Zonal component, or east-speed $u_{\mathrm{g}}$; (b) meridional component, or north-speed $v_{\mathrm{g}}$; (c) amplitude of horizontal velocity; (d) phase angle (from east direction), of the SGC estimated using ITG-Grace2010S geoid model. (Color figure available online.) 
component. Nevertheless, the westward North Equatorial Current (NEC) and the eastward North Equatorial Counter Current (NECC) in the North Pacific can be readily identified to reach values higher than $30 \mathrm{~cm} / \mathrm{s}$ in the zonal component. Although not as clear, similar behavior as NECC can be seen in the North Atlantic Ocean. Recognizing the need for a more exigent filter, here we shall not dwell upon the SGC solutions in the equatorial band.

Figure 2 gives the corresponding mean SGC patterns based on the state-of-the-art GRACE geoid model. Here we have expanded the latter up to Nmax $=160$, potentially resolving spatial scales at $125 \mathrm{~km}$. Overall, due to the lower Nmax and hence lower resolution, the equatorial band appears less noisy. However, as compared to the GOCE results of Figure 1, it is obvious that Figure 2 misses the finer signals that would otherwise provide more detailed results at middle and higher latitudes where the quality of the satellite gravity data are higher.

Horizontal velocity field of the ocean current climatology from in situ drifter buoy data are shown in Figure 3. Barring the uncertainties introduced upon the use of models to correct for the Ekman transport (see above), these results should provide an effective tool to validate our SGC results. Figure 4 gives the corresponding climatology SGC computed from the OGCM ECCO long-term output of SSH. Indeed, similarities are found between the GOCE-based SGC results (Figure 1) and those from in situ drifter buoy data (Figure 3), while both show much stronger velocities and much finer details than the GRACE-based SGC (Figure 2) and the ECCO simulated surface ocean currents (Figure 4).

(a)

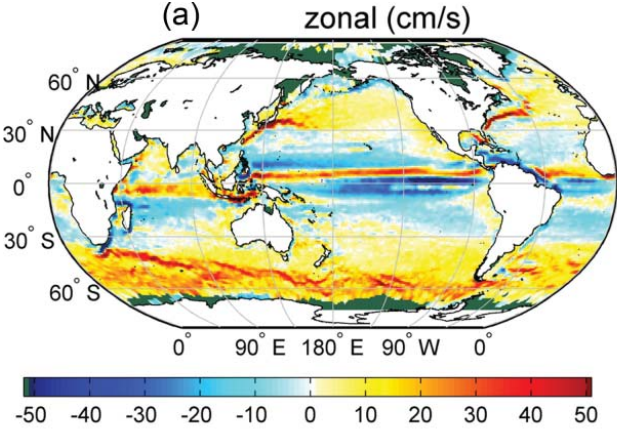

(c) amplitude $(\mathrm{cm} / \mathrm{s})$

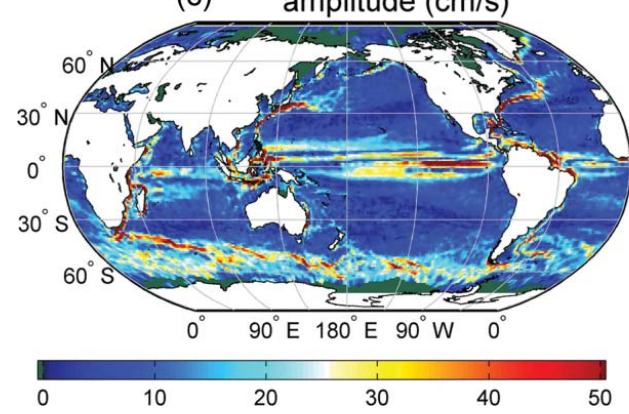

(b) meridional $(\mathrm{cm} / \mathrm{s})$

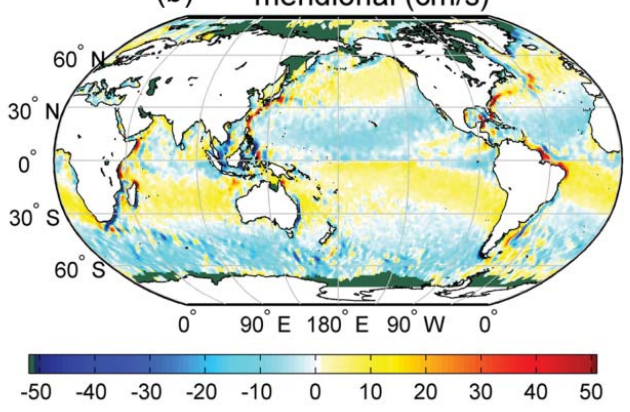

(d)

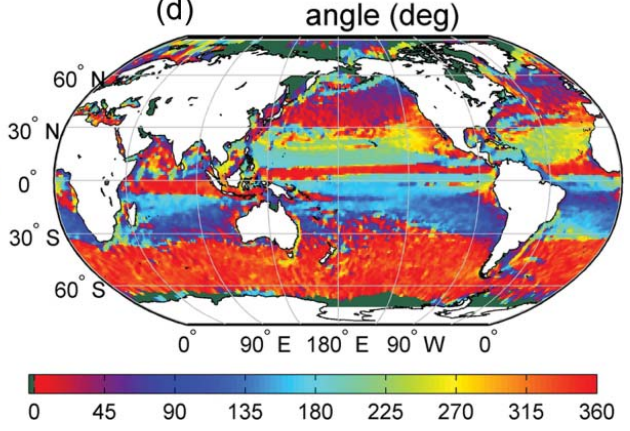

Figure 3. (a) Zonal component, or east-speed $u_{\mathrm{g}}$; (b) meridional component, or north-speed $v_{\mathrm{g}}$; (c) amplitude of horizontal velocity; (d) phase angle (from east direction), of the SGC estimated for the drifter buoys. (Color figure available online.) 

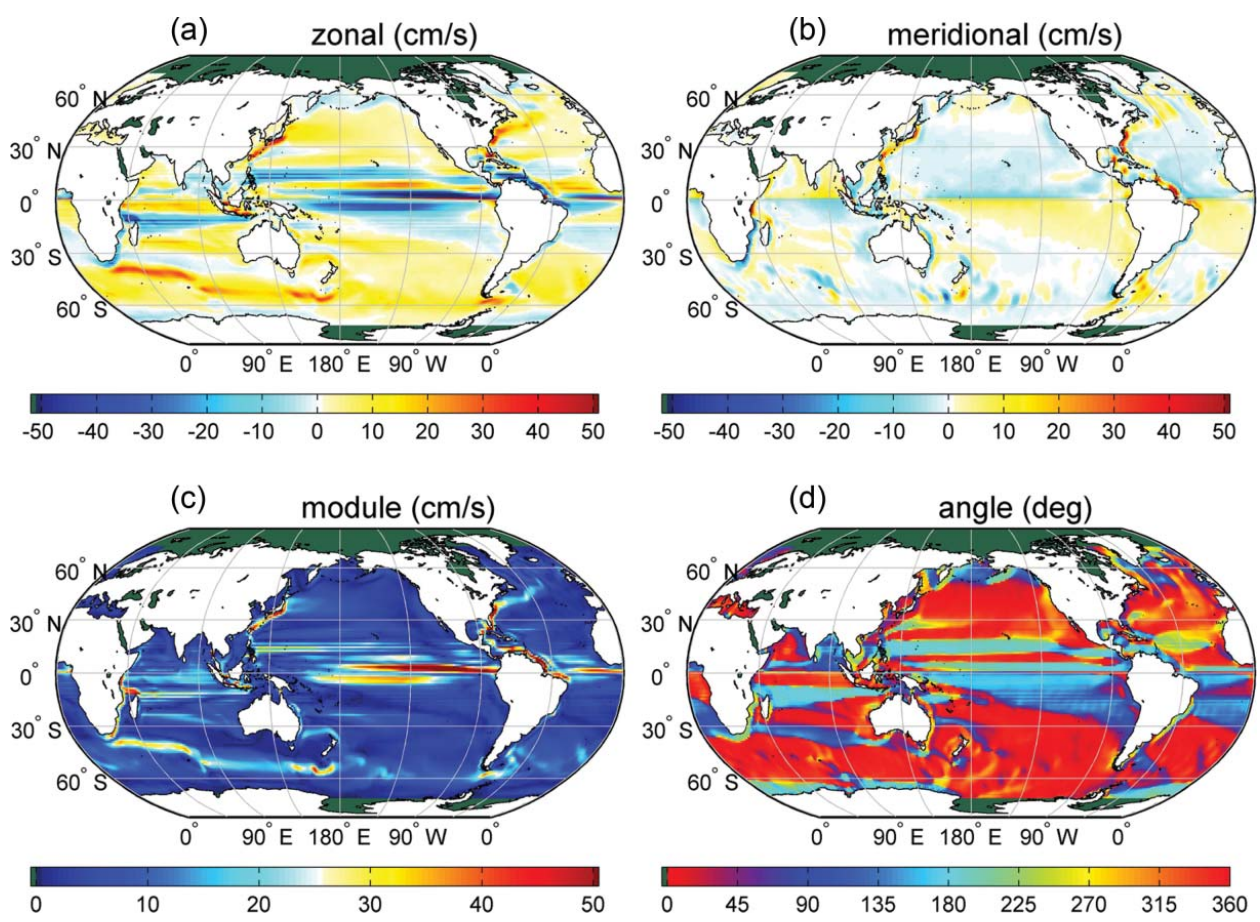

Figure 4. (a) Zonal component, or east-speed $u_{\mathrm{g}}$; (b) meridional component, or north-speed $v_{\mathrm{g}}$; (c) amplitude of horizontal velocity; (d) phase angle (from east direction), of the SGC estimated using SSH simulations by the ECCO model. (Color figure available online.)

In order to deeper examine and compare the results, in the following subsections we focus on three of the major currents areas of the Ocean: the Gulf Stream being the western-boundary currents in the North Atlantic; the Kuroshio as the western-boundary current in the North Pacific; and the Antarctica Circumpolar Current (ACC) in the Southern Ocean.

\subsection{Zoom in on the North Atlantic Ocean}

Figure 5 zooms in and compares all four solutions of the velocity amplitude in the region of the North Atlantic Ocean $\left[22^{\circ} \mathrm{N} 70^{\circ} \mathrm{N}\right] \times\left[85^{\circ} \mathrm{W} 0^{\circ} \mathrm{E}\right]$. The general circulation pattern of the area (Fratantoni 2001) is clearly captured by the GOCE-based results shown in Figure 5a, with much higher details than those based on GRACE, drifter buoys, and ECCO model in Figures 5b, c, and d, respectively. The Gulf Stream, following the eastern coastlines of the North America from the Florida tip is depicted with amplitudes higher than $50 \mathrm{~cm} / \mathrm{s}$. As a continuation of the Gulf Stream the North Atlantic Drift bifurcates into two branches of lesser intensity: the Norwegian Current heading northward along the coast of Norway with amplitudes up to $30 \mathrm{~cm} / \mathrm{s}$, and another heading southward towards the Canary Islands. The East Greenland Current flows southward along the east coast of Greenland, as does the Labrador Current that continues off the coast of Canada, both with speed up to $30 \mathrm{~cm} / \mathrm{s}$. The Azores current, located around $32^{\circ} \mathrm{N}$ x $40^{\circ} \mathrm{W}-30^{\circ} \mathrm{W}$, illustrates the capability of GOCE to resolve small-scale features of ocean circulation. 
(a)

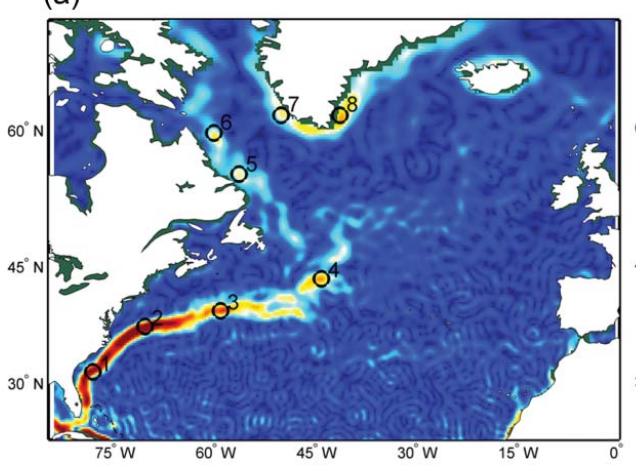

(c)

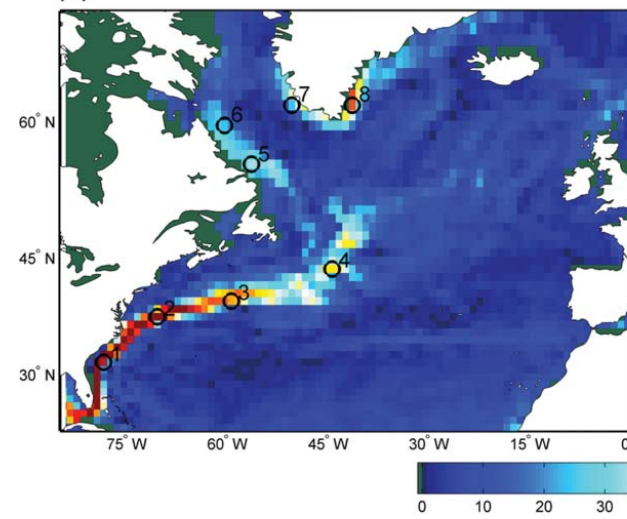

(b)

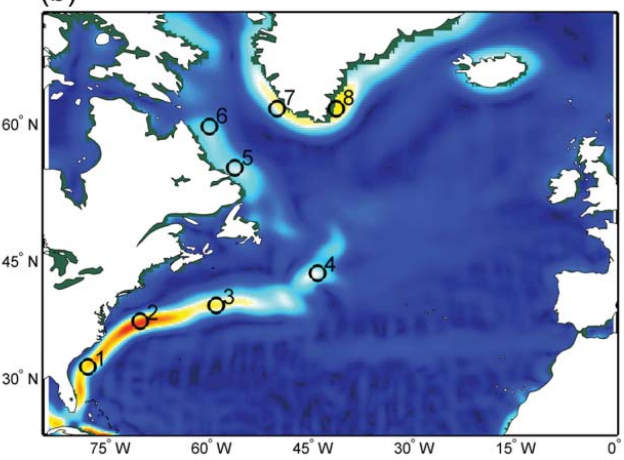

(d)

Figure 5. Zoom-in on the North Atlantic Ocean velocities estimates from (a) the SGC using the GOCE-derived geoid (Figure 1c); (b) the SGC using the GRACE-derived geoid (Figure 2c); (c) the in situ drifters measurements (Figure 3c); and (d) the velocities derived from the SSH simulated by ECCO (Figure 4c). (Color figure available online.)

We sample eight locations with significant velocity, as indicated in Figure 5, as small circles numbered from 1 to 8 (1-4 in the Gulf Stream, 5-6 in the Labrador Current, and 7-8 in the Western and Eastern Greenland Current). Table 1 compares their estimated SGC velocity amplitudes (the GOCE and GRACE values are averaged over a 1 degree grid). For reference, the RMS differences relative to the GOCE values are also given. The GOCE solution is shown to be in good agreement with measurements from drifters, particularly in the Gulf Stream (locations 1-4), where the GOCE values double the GRACE values. In the Labrador Current (locations 5-6), the GOCE velocities are a bit stronger than both the GRACE and drifters, which agree well with each other. In the Greenland current (locations 7-8), GOCE and GRACE values are similar. In general, the drifter measurements are closest to the GOCE results with RMS difference of $10.4 \mathrm{~cm} / \mathrm{s}$, while the ECCO values are significantly weaker than all the others.

\subsection{Zoom in on the Kuroshio}

Figure 6 zooms-in on the velocity amplitude in the Kuroshio region of the North-Western Pacific Ocean $\left[20^{\circ} \mathrm{N} 45^{\circ} \mathrm{N}\right] \times\left[120^{\circ} \mathrm{E} 170^{\circ} \mathrm{W}\right]$ for all four solutions. The general circulation 


\section{Table 1}

Velocities estimation for several locations at the North Atlantic Ocean (Figure 5). Last row lists the RMS of those velocities relative to the GOCE-induced velocities

\begin{tabular}{rrrrrrr}
\hline & lat $\left({ }^{\circ} \mathrm{N}\right)$ & lon $\left({ }^{\circ} \mathrm{E}\right)$ & GOCE & GRACE & DRIFTERS & ECCO \\
\hline 1 & 31,5 & 281,5 & 73,1 & 49,3 & 74,1 & 52,2 \\
2 & 37,5 & 289,5 & 83,5 & 58,8 & 94,7 & 30,1 \\
3 & 39,5 & 300,5 & 58,8 & 43,3 & 53,6 & 17,4 \\
4 & 43,5 & 315,5 & 50,8 & 35,6 & 48,4 & 16,5 \\
5 & 55,5 & 303,5 & 38 & 34,3 & 33,7 & 9,3 \\
6 & 59,5 & 299,5 & 41,4 & 30 & 24,2 & 7,5 \\
7 & 61,5 & 309,5 & 41,5 & 41,2 & 24,4 & 0,8 \\
8 & 61,5 & 318,5 & 50,3 & 48 & 60,4 & 4,8 \\
& & & RMS & 15 & 10,4 & 38,5 \\
\hline
\end{tabular}

pattern of the Kuroshio (Nakano et al. 2008) is clearly seen in the maps from GOCE, GRACE and drifters. The GOCE spatial pattern is quite similar to that of both GRACE and the drifters, while the ECCO results are poorer as missing some relatively strong signals of Kuroshio and its extension. The end of the Kuroshio is spread out to the open Pacific Ocean in several branches. The Subarctic front around $40^{\circ} \mathrm{N} \times 150^{\circ} \mathrm{W}-170^{\circ} \mathrm{W}$ is seen to reach velocities of around $30-40 \mathrm{~cm} / \mathrm{s}$.

Table 2 gives the velocity amplitudes for four locations (labeled 1-4 in Figure 6). Same remarks as in Table 1 can be made with respect to the GRACE, drifters, and ECCO results in relation to the GOCE results, in terms of general comparisons as well as RMS differences.

(a)

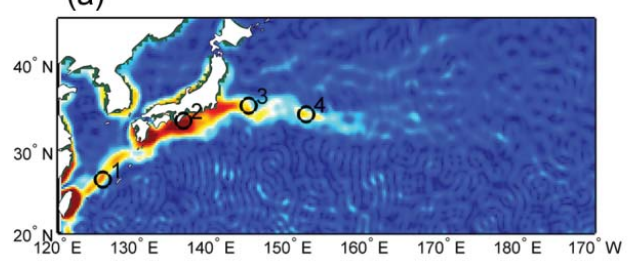

(c)

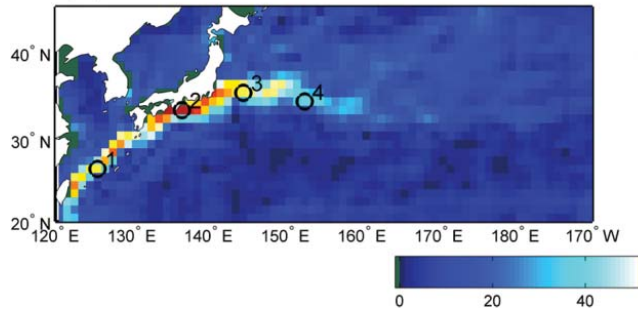

(b)

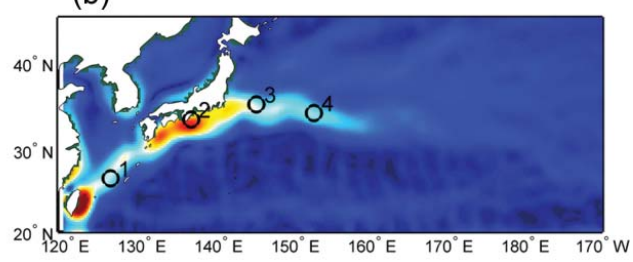

(d)

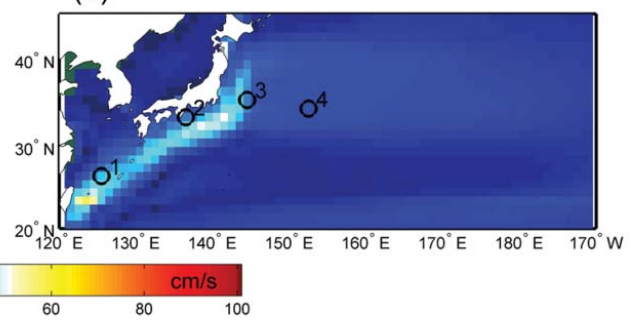

Figure 6. Zoom-in on the Kuroshio velocities estimates from (a) the SGC using the GOCE-derived geoid (Figure 1c); (b) the SGC using the GRACE-derived geoid (Figure 2c); (c) the in situ drifters measurements (Figure 3c); and (d) the velocities derived from the SSH simulated by ECCO (Figure $4 c)$. (Color figure available online.) 
Table 2

Same as Table 1 but for locations at the Kuroshio (Figure 6)

\begin{tabular}{rccrccc}
\hline & lat $\left({ }^{\circ} \mathrm{N}\right)$ & lon $\left({ }^{\circ} \mathrm{E}\right)$ & GOCE & GRACE & DRIFTERS & ECCO \\
\hline 1 & 26,5 & 125,5 & 69,3 & 46,3 & 59,5 & 34,4 \\
2 & 33,5 & 136,5 & 116,2 & 80,2 & 98,2 & 31,5 \\
3 & 35,5 & 144,5 & 59,2 & 47,2 & 58,5 & 13,9 \\
4 & 34,5 & 152,5 & 54,5 & 41,3 & 38,2 & 13,4 \\
& & & RMS & 23,1 & 13,1 & 55,1 \\
\hline
\end{tabular}

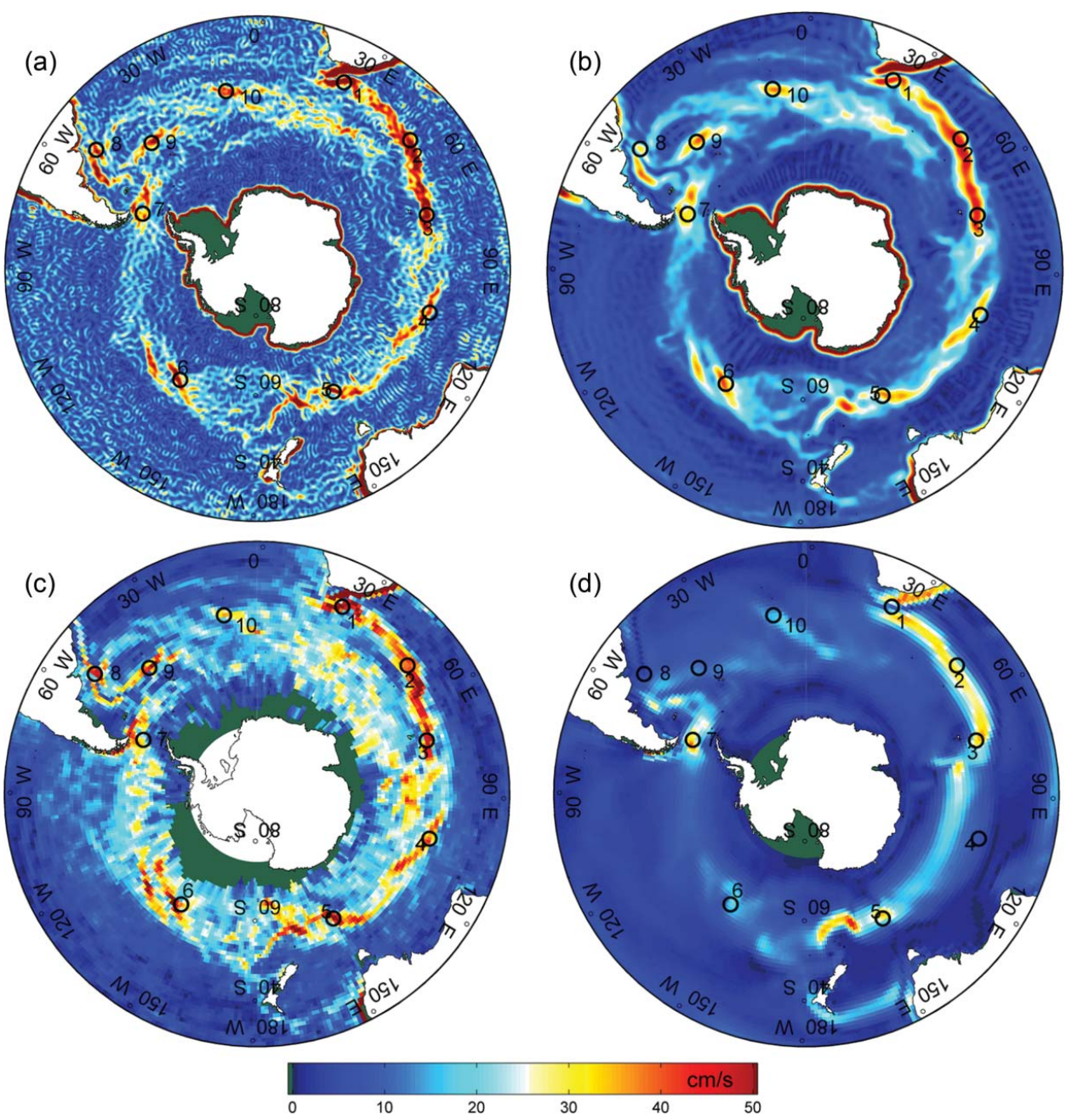

Figure 7. Zoom-in on the Southern Ocean velocities estimates from (a) the SGC using the GOCEderived geoid (Figure 1c); (b) the SGC using the GRACE-derived geoid (Figure 2c); (c) the in situ drifters measurements (Figure 3c); and (d) the velocities derived from the SSH simulated by ECCO (Figure 4c). (Color figure available online.) 


\subsection{Zoom in on the Southern Ocean}

Figure 7 shows the corresponding zooms-in for the Southern Ocean $\left[90^{\circ} \mathrm{S} 27^{\circ} \mathrm{S}\right] \mathrm{x}\left[0^{\circ} \mathrm{E}\right.$ $\left.360^{\circ} \mathrm{E}\right]$. The GOCE-based results clearly depict the general circulation pattern of the region (Rintoul et al. 2001). In the South Atlantic, the western-boundary of the Brazil Current, with speed close to $30 \mathrm{~cm} / \mathrm{s}$, flows southward along the central South American coast, turns east off the Río de la Plata to become the South Atlantic Current with moderate speed of about $20 \mathrm{~cm} / \mathrm{s}$, until reaching the African coast and forming the Benguela Current that goes northward with speed close to $25-30 \mathrm{~cm} / \mathrm{s}$. The Antarctic coastal current that flows westward following the coast of Antarctica meets the eastward-flowing ACC at the Drake Passage, emerging as the Malvinas (Falkland) current as a branch of the ACC that flows northward along the continental shelf of Argentina until merging with the Brazil Current. In the South Pacific, the western boundary current of East Australia flows southward from the Coral Sea along the east coast of Australia into the Tasmania Sea, with speed around $40 \mathrm{~cm} / \mathrm{s}$. The South Pacific Current then flows eastward and approaches the coast of Peru to become the Peru Current flowing northward till it meets with the westward South Equatorial Current. In the south eastern Indian Ocean, the southward Agulhas current follows the Mozambique current, both with amplitudes above $50 \mathrm{~cm} /$, to become the Agulhas return with speed around $40 \mathrm{~cm} / \mathrm{s}$.

The described GOCE-based pattern agrees reasonably well with that based on GRACE geoid (Figure 7b), while a better agreement is seen with results from drifters (Figure 7c). Some significant differences appear only at the higher latitude areas approaching the Antarctic coast, which could be attributed to the lower quality of the altimetric MSST there (as opposed to the GOCE geoid) because the merged altimetric solution is weaker in such areas considering the orbit inclinations of the satellites (T/P and Jason at $66^{\circ}$, ERS and Envisat at $82^{\circ}$ and Geosat, GFO at $72^{\circ}$ ). In addition, Niiler et al. (2003) found strong discrepancies for sea level estimated from drifter at this area due to strong winds and ocean waves contaminating the drifter estimation of the currents with ageostrophic components.

Table 3 provides the velocity estimations for ten locations with strong amplitude (see Figure 7). In general, the currents estimated by GOCE are stronger than all other solutions, being closest to the drifter measurements with RMS difference of only $8.6 \mathrm{~cm} / \mathrm{s}$, and

Table 3

Same as Table 1 but for locations at the Southern Ocean (Figure 7)

\begin{tabular}{rrrcccr}
\hline & lat $\left({ }^{\circ} \mathrm{N}\right)$ & lon $\left({ }^{\circ} \mathrm{E}\right)$ & GOCE & GRACE & DRIFTERS & ECCO \\
\hline 1 & $-38,5$ & 24,5 & 58,3 & 43,2 & 56,6 & 7,2 \\
2 & $-40,5$ & 49,5 & 50,4 & 44,2 & 38,2 & 27,3 \\
3 & $-45,5$ & 72,5 & 55,5 & 44,1 & 47,9 & 32,7 \\
4 & $-45,5$ & 104,5 & 40,9 & 26,4 & 39,4 & 7,1 \\
5 & $-53,5$ & 148,5 & 33,7 & 31,5 & 53,5 & 28,3 \\
6 & $-56,5$ & 214,5 & 31,5 & 33,3 & 39,1 & 18,2 \\
7 & $-58,5$ & 295,5 & 37,4 & 31,4 & 30,7 & 31,4 \\
8 & $-39,5$ & 306,5 & 44,9 & 30,1 & 46,9 & 2,5 \\
9 & $-48,5$ & 319,5 & 45,8 & 36,7 & 48 & 12,1 \\
10 & $-44,5$ & 349,5 & 40,8 & 34,6 & 36,2 & 15,9 \\
& & & RMS & 10 & 8,6 & 29,3 \\
\hline
\end{tabular}


somewhat lower agreement with velocities estimated from GRACE at RMS difference of about $10 \mathrm{~cm} / \mathrm{s}$.

\section{Discussion and Conclusions}

From the synoptic results based on just 1 cycle of GOCE data as presented here, we see that the SGC can be reliably resolved from space-based geodetic observations with a spatial resolution down to $\sim 83 \mathrm{~km}$, thus reaching a main goal of the GOCE mission. Specifically, our ocean MDT determined geodetically as above is limited by the maximum degree of the harmonic expansion of the geoid model and hence by the associated omission errors. The signal-to-noise ratio drastically decreases with increasing degree, thus we apply a filter of $83 \mathrm{~km}$ of half wavelength and retain the full potential in the extent of spatial resolution that is feasible from the GOCE geoid model.

With GOCE geoid we have obtained the mean SGC in extratropical latitudes, particularly the Gulf Stream, the Kuroshio, and the Antarctic Circumpolar Current. We have compared them with those from the state-of-the-art GRACE geoid, in situ drifter buoys measurements, and simulations from the ECCO model. While large spatial scale features are shared by all sets of results to different extent, the GOCE-based results clearly provide the highest spatial resolution and level of details.

In contrast to GRACE, that has revolutionized the time variable gravity research, GOCE is measuring the Earth's static gravity field, and hence the MDT, with unprecedented accuracy and spatial resolution. The higher resolution provided by GOCE allows to resolve weaker and narrower currents, for example the Azores current in the North Atlantic or the subarctic front in the North-Western Pacific, that GRACE-based results fail to capture.

The GOCE-based estimation of the mean SGC velocities have been shown to agree quite well with the in situ drifters results in both the mean velocity and space pattern, confirming the robustness of observations of both techniques. That given, it is recognized that a great advantage of the GOCE-based (or for that matter GRACE-based) SGC over the mean velocity field from the drifters is that the former can readily yield the time-variable SGC, which the latter is inadequate to do with sparse observations.

Velocity field output from the ECCO OGCM are obviously poorer in geographical resolution with velocity magnitude significantly lower than the other solutions. The latter is due to a recognized general underestimation of the ocean variability by OGCMs (e.g., Chao et al. 2003). This would make necessary the use of regional eddy-resolving model for further studies of the ocean circulation on basin scales.

We have only dealt with the mean SGC. Further studies based on the same data sets and a similar methodology could readily estimate the global SGC as a function of time, at a desired temporal resolution of, say, weekly. This can be particularly relevant to research and applications, opening a new frontier in the study of time-variable mesoscale phenomena such as eddies, gyres, and flow bifurcations with unprecedented spatial resolution down to finer than $100 \mathrm{~km}$.

\section{Acknowledgements}

This work is supported by the projects AYA2009-07981 and CGL2010-12153-E from the Spanish Department of Science and Innovation (MICINN), the Taiwan National Science Council (Grant No. 98-2116-M-001-015), the National Natural Science Foundation of China (NSFC) (Grant No. 11043008 and 11173050) and the key program of Chinese Academy of Sciences (Grant No. KJCX2-EW-T03). We are grateful to ESA for providing 
the GOCE gravity data, AVISO for providing the ocean altimetry data, NOAA for the ocean drifters data, and the ECCO project for the model simulations data.

\section{References}

Adcroft, A., J. M. Campin, P. Heimbach, C. Hill, and J. Marchall. 2002. MITgcm Release 1. http:// mitgcm.org/sealion

Bettapdur, B. 2007a. Level-2 Gravity Field Product User Handbook GRACE 327-734. http:// podaac.jpl.nasa.gov/grace/documentation.html

Bettapdur, B. 2007b. CSR Level-2 Processing Standards Document for Product Release 04 GRACE 327-742. http://podaac.jpl.nasa.gov/grace/documentation.html

Bingham, R., K. Haines, and C. Hughes. 2008. Calculating the ocean's mean dynamictopography from a mean sea surface and a geoid. J. Atmos. Ocean. Tech. 25(10):1808-1822. doi: 10.1175/2008JTECHO568.1.

Bingham, R. J., P. Knudsen, O. B. Andersen, and R. Pail. 2011. An initial estimate of the North Atlantic steady-state geostrophic circulation from GOCE. Geophys. Res. Lett. 38:L01606. doi: 10.1029/2010GL045633.

Birol, F., J. M. Brankart, J. M. Lemoine, P. Brasseur, and J. Verron. 2005. Assimilation of satellite altimetry referenced to the new GRACE geoid estimate. Geophys. Res. Lett. 32:L06601. doi: 10.1029/2004GL021329.

Chao, B. F., A. Y. Au, J.-P. Boy, and C. Cox. 2003. Time-variable gravity signal of an anomalous redistribution of water mass in extratropic Pacific during 1998-2002. Geochem. Geophys. Geosyst. 4(11): 1096. doi: 10.1029/2003GC000589.

Drinkwater, M., R. Floberghagen, R. Haagmans, D. Muzi, and A. Popescu. 2003. GOCE: ESA's first Earth Explorer Core mission. Space Sci. Rev. 108(1-2):419-432. In ed. G.B. Beutler, M. R. Drinkwater, R. Rummel, and R. von Steiger, Earth Gravity Field from Space - From Sensors to Earth Sciences. Space Sciences Series, ISSI, 18: 419-432. Dordrecht, Netherlands: Kluwer Academic Publishers.

EGG-C (European GOCE Gravity Consortium). 2009. GOCE high level processing facility: GOCE level 2 product data handbook. GO-MA-HPF-GS-0110. http://www.esa.int/esaLP/ GTCVCKSC_LPgoce_0.html

Foerste, C., F. Flechtner, R. Schmidt, R. Stubenvoll, M. Rothacher, J. Kusche, H. Neumayer, R. Biancale, J. M. Lemoine, F. Barthelmes, S. Bruinsma, R. Koenig, and U. Meyer. 2008. EIGENGL05C - a new global combined high-resolution GRACE-based gravity field model of the GFZ-GRGS cooperation. Geophys. Res. Abs. 10:EGU2008-A-03426.

Fratantoni, D. M. 2001. North Atlantic surface circulation during the 1990s observed with satellitetracked drifters. J. Geophys. Res. 106:22,067. doi: 1'.1029/2000JC000730.

Fukumori, I. 2002. A PARTITIONED Kalman filter and smoother. Mon. Wea. Rev. 130:1370-1383.

Gill, A. E. 1982. Atmosphere-Ocean Dynamics, International Geophysics Series, 30. Oxford:Academic Press.

Heiskanen, W. A., and H. Moritz. 1967. Physical Geodesy. San Francisco: W. H. Freeman and Company.

Hernandez, F., and P. Schaeffer, 2001. The CLS01 MSS: A validation with the GSFC00.1 surface. Tech. Rep., CLS, Ramonville St Agne.

Hughes, C. W., and R. J. Bingham. 2006. An oceanographer's guide to GOCE and the geoid. Ocean Sci. Discuss. 3:1543-1568. doi: 10.5194/osd-3-1543-2006.

Knudsen, P., O. Andersen, R. Bingham, and M. H. Rio. 2011. A global mean dynamic topography and ocean circulation estimation using a preliminary GOCE gravity model. J. Geodesy doi: 10.1007/s00190-011-0485-8.

Kurtenbach, E., T. Mayer-Gürr, and A. Eicker. 2009. Deriving daily snapshots of the Earth's gravity field from GRACE L1B data using Kalman filtering. Geophys. Res. Lett. 36:L17102. doi: 10.1029/2009GL039564. 
Lagerloef, G. S. E., G. T. Mitchum, R. B. Lukas, and P. P. Niiler. 1999. Tropical Pacific nearsurface currents estimated from altimeter, wind, and drifter data. J. Geophys. Res. 104(C10): 23,313-23,326. doi: 10.1029/1999JC900197.

Lumpkin, R., and Z. Garraffo. 2005. Evaluating the decomposition of tropical Atlantic drifter observations. J. Atmos. Oceanic Techn. I 22:1403-1415.

Maximenko, N., P. P. Niiler, L. Centurioni, M.-H. Rio, O. Melnichenko, D. Chambers, V. Zlotnicki, and B. Galperin. 2009. Mean dynamic topography of the ocean derived from satellite and drifting buoy data using three different techniques. J. Atmos. Oceanic Technol. 26:1910-1919.

Nakano, H., H. Tsujino, and R. Furue. 2008. The Kuroshio Current system as a jet and twin "relative" recirculation gyres embedded in the Sverdrup circulation. Dynam. Atmos. Oceans. 45:135-164. doi: 10.1016/j.dynatmoce.2007.09.002.

Niiler, P. P., and J. D. Paduan. 1995. Wind-driven motions in the northeast Pacific as measured by Lagrangian drifters. J. Phys. Oceanogr. 25:2819-2830.

Niiler, P. P. 2001. The world ocean surface circulation. In ed. J. Church and J. Gould, Ocean Circulation and Climate, 193-204, volume 77, of International Geophysics Series. New York: Academic Press.

Niiler, P. P., N. A. Maximenko, and J. C. McWilliams. 2003. Dynamically balanced absolute sea level of the global ocean derived from near-surface velocities observations. Geophys. Res. Lett. 30(22): 2164. doi: 10.1029/2003GRL018628.

Pail, R., S. Bruinsma, F. Migliaccio, C. Foerste, H. Goiginger, W. D. Schuhand, E. Hoeck, M. Reguzzoni, J. M. Brockmann, O. Abrikosov, M. Veicherts, T. Fecher, R. Mayrhofer, I. Krasbutter, F. Sanso, and C. Tscherning. 2011. First GOCE gravity field models derived by three different approaches. J Geodesy 85:819-843. doi: 10.1007/s00190-011-0467-x.

Pazan, S. E., and P. P. Niiler. 2000: Recovery of near-surface velocity from undrogued drifters. $J$. Atmos. Oceanic Technol. 18:476-489.

Qiu, B., and S. Chen. 2005. Variability of the Kuroshio extension jet, recirculation gyre, and mesoscale eddies on decadal time scales. J. Phys. Oceanogr. 35:2090-2103.

Ralph, E. A., and P. P. Niiler. 1999. Wind-driven currents in the Tropical Pacific. J. Phys. Oceanogr. 29:2121-2129.

Rintoul, S. R., C. W. Hughes, and D. Olbers. 2001. The Antarctic circumpolar current system. In ed. G. Siedler, J. Church, and J. Gould, Ocean Circulation and Climate Observing and Modelling the Global Ocean. New York:Academic Press. doi: 10.1016/S0074-6142(01)80124-8.

Smith, D. U. 1998. There is no such thing as "The" EGM96 geoid: Subtle points on the use of a global geopotential modeI. GeS Bulletin No. 8, 17-28. Milan, Italy:International Geoid Service.

Sybrandy, A. L., and P. P. Niiler. 1991. WOCE/TOGA Lagrangian drifter construction manual. WOCE Rep. 63, SOI Ref. 91/6. La Jolla, CA: Scripps Inst. of Oceanogr.

Tapley, B. D., D. P. Chambers, S. Bettadpur, and J. C. Ries. 2003. Large-scale ocean circulation from the GRACE GGM01 Geoid. Geophys. Res. Lett. 30(22): 2163. doi: 10.1029/2003GL018622.

Tapley, B. D., S. Bettadpur, M. Watkins, and C. Reigber. 2004. The gravity recovery and climate experiment: Mission overview and early results. Geophys. Res. Lett. 31:L09607. doi: 10.1029/2004GL019920.

Thomas, M. 2002. Ocean induced variations of Earth's rotation - results from a simultaneous model of global circulation and tides. Ph.D. dissertation, Univ. of Hamburg, Germany. 